CLINICAL STUDY

\title{
Usefulness of adrenal scintigraphy in the follow-up of adrenocortical incidentalomas: a prospective multicenter study
}

\author{
Cédric Fagour ${ }^{1}$, Stéphane Bardet ${ }^{3}$, Vincent Rohmer ${ }^{4}$, Yannick Arimone ${ }^{5}$, Pierre Lecomte ${ }^{6}$, Nathalie Valli ${ }^{2}$ \\ and Antoine Tabarin ${ }^{1}$ \\ Departments of ${ }^{1}$ Endocrinology and ${ }^{2}$ Nuclear Medicine, University Hospital of Bordeaux, Hôpital Haut Leveque, Avenue de Magellan, 33600 Pessac, \\ France, ${ }^{3}$ Department of Nuclear Medicine, Centre François Baclesse, 14076 Caen, France, ${ }^{4}$ Department of Endocrinology, University Hospital of Angers, \\ 49033 Angers, France, ${ }^{5}$ Department of Pharmacology, INSERM U 657, University of Bordeaux 2, Bordeaux 33000, France and ${ }^{6}$ Department of \\ Endocrinology, University Hospital of Tours, 37044 Tours Cedex 9, France
}

(Correspondence should be addressed to A Tabarin; Email: antoine.tabarin@chu-bordeaux.fr)

\begin{abstract}
Objectives: Prognostic factors for progression of benign adrenocortical adenomas (AI) remain poorly known. We assessed the usefulness of ${ }^{131}$ I- 6 - $\beta$-iodomethylnorcholesterol scintigraphy (IMS) to predict the occurrence of adrenal hyperfunction or mass enlargement.

Design: Fifty-one consecutive inpatients with unilateral AI and normal 24-h urinary free cortisol (UFC) were enrolled in a multicenter observational prospective study to investigate the relationship between the scintigraphic pattern and the progression of biological abnormalities of the hypothalamopituitary-adrenal axis or tumor size.

Results: Biochemically defined 'subclinical' Cushing's syndrome (SCS) was found at baseline in $47 \%$ of patients. Unilateral uptake (UU) was significantly associated with SCS $(P<0.05)$. During the follow-up $(4.3 \pm 1.6$-year): $53 \%$ of patients showed unchanged hormonal evaluation, $29 \%$ displayed intermittent SCS and 18\% showed definitive hormonal progression of SCS but without overt biochemical hypercortisolism. UU was associated with persistence of SCS and hormonal progression $(P<0.01)$. In multivariate analysis, UU and impaired $1 \mathrm{mg}$ dexamethasone suppression were independently associated with hormonal progression. Three patients with UU developed clinical CS despite persistently normal UFC. Tumor size increased in $10 \%$ patients and was not associated with any scintigraphic pattern.

Conclusion: Evolution of SCS toward overt biochemical CS in patients with AI is a rare event during a 4-year follow-up. UU is predictive for the occurrence of SCS, its persistence and progression within the spectrum of SCS. Further studies aiming to establish the clinical consequences of SCS are needed to recommend IMS as a complementary evaluation in patients with AI and biochemical SCS.
\end{abstract}

European Journal of Endocrinology 160 257-264

\section{Introduction}

Approximately, 70 percent of adrenal incidentalomas discovered in patients without extra-adrenal malignancy are benign adrenocortical adenomas (1-3). Several studies have shown that a subset of these tumors secrete a mild excess of cortisol leading to the concept of 'subclinical' Cushing's syndrome (SCS) and 'subclinical' cortisol-secreting adenomas (SCSA) (2). However, SCS is a heterogeneous condition and various biochemical criteria, alone or in combination, have been employed to define it (4). From a historical perspective, adrenal scintigraphy using 19-iodocholesterol allowed recognition of this entity where there was exclusive tumor uptake $(5,6)$. Later on, we and other groups demonstrated a clear relationship between the secretory autonomy of the adrenal tumor and the scintigraphic pattern. Indeed, unilateral norcholesterol tumor uptake was associated with increased midnight plasma cortisol concentrations, decreased $0800 \mathrm{~h}$ plasma ACTH and decreased cortisol suppressibility by dexamethasone compared with bilateral scintigraphic uptake (7-10). However, due to the paucity of available data on its clinical usefulness, radiocholesterol scintigraphy was not recommended as part of the evaluation of benign adrenocortical incidentalomas (AI) by the NIH conference consensus (3).

The natural history of AI and the risk that such lesions might evolve toward overt hypercortisolism remains controversial, since only a few prospective studies have been conducted (11-14). Among these, the occurrence of overt clinical CS ranges from 0 to $12.5 \%$, whereas the development over time of new subtle biochemical abnormalities is likely to be more frequent $(11-16,22,30)$.

Identification of prognostic factors would be useful to select patients at risk for disease progression, to adapt 
the follow-up and/or to decide whether to proceed to surgery. Few studies have addressed this issue. Tumor size $\geq 3 \mathrm{~cm}$ at diagnosis $(14,16)$ and exclusive tumor radiocholesterol uptake (14) were found to be associated with the occurrence of endocrine hyperfunction. On the other hand, a recent prospective study conducted by Bernini et al. (12) did not find any baseline predictor for disease progression. However, adrenal scintigraphy was not performed in this study.

The aim of the present study was to prospectively assess the long-term clinical, morphological, and hormonal outcome of patients with adrenocortical incidentalomas and to determine whether the uptake pattern on radiocholesterol scintigraphy could predict the occurrence of adrenal hyperfunction or mass enlargement.

\section{Patients and methods}

\section{Patients}

Sixty-one consecutive patients with AI were enrolled in a prospective study including four French university hospitals (Angers, Bordeaux, Caen, and Tours) from January 1996 to December 2001. To be included, patients had to fulfill the following criteria: imaging characteristics suggesting benign adrenocortical adenoma at CT scan analyzed by an experienced radiologist, defined on size $\leq 40 \mathrm{~mm}$, low-attenuation value $(<10 \mathrm{UH})$, and a washout at $10-15 \mathrm{~min}$ of more than $50 \%$ after i.v. contrast administration (17); lack of specific signs of CS (muscle wasting, purple striae, skin atrophy, spontaneous ecchymosis) after careful examination by an experienced endocrinologist; 24-h urinary free cortisol (UFC) excretion in the normal range; normal plasma renin activity and aldosterone in supine and upright positions and normal 24-h urinary metanephrine excretion.

The study was approved by the Comité Consultatif de Protection des Personnes dans la Recherche Biomédicale de Basse-Normandie. Each patient included in the study gave written informed consent.

\section{Study design}

Baseline and follow-up investigations All patients were explored as in-patients. Baseline investigations consisted of clinical examination, CT scan, adrenal scintigraphy and hormonal measurements. Biochemical hypothalamo-pituitary-adrenal (HPA) axis evaluation included measurements of midnight and $0800 \mathrm{~h}$ plasma cortisol, $0800 \mathrm{~h}$ plasma ACTH, cortisol after $1 \mathrm{mg}$ dexamethasone suppression test (DST) and 24-h UFC.

After initial diagnosis, patients were reinvestigated at 1 year intervals with the same clinical, radiological and hormonal investigations. In addition, 23 patients had a second adrenal scintigraphy at the end of their follow up.
Definition and criteria of outcome From a hormonal perspective, patients were considered at baseline as having either SCSA or non-secreting adenomas (NSA). SCSA was arbitrarily defined as the presence of at least two HPA axis abnormalities including low $0800 \mathrm{~h}$ plasma ACTH, elevated 2400/0800 h cortisol ratio, elevated midnight plasma cortisol, with a compulsory condition of impaired serum cortisol suppression after $1 \mathrm{mg}$ DST ( $50 \mathrm{nmol} / \mathrm{l}$ ). Importantly, all patients including those classified as having SCSA displayed normal 24-h UFC at baseline evaluation.

During follow-up, biochemical features were defined as persistent when found at baseline and at each follow-up evaluation. Otherwise, they were considered as intermittent. Patients were consequently categorized as having persistent SCSA, persistent NSA or intermittent SCSA.

Hormonal progression was defined as follows: patient with NSA at baseline in whom at least two HPA axis abnormalities appeared and persisted during follow-up (e.g. switch from NSA to SCSA); patients with SCSA at baseline in whom at least one additional HPA axis abnormality appeared and persisted over time. Overt biochemical CS was defined by the occurrence of elevated UFC $(>1.5$ above the upper limit of the normal range of the assay).

Clinical progression was defined as the emergence of at least one specific sign of CS considered as obvious and persistent by the referent endocrinologist regardless of the results of hormonal evaluation.

Tumoral progression was defined on CT scan as a $1 \mathrm{~cm}$ or greater increase in tumor diameter.

The decision to proceed to surgery was considered at each follow-up evaluation in the absence of the adequate control of diabetes or hypertension, the occurrence of clinical CS, the development of overt biochemical CS or significant growth of the adrenal mass.

\section{Methods}

Biochemical testing Hormonal measurements were performed in the reference laboratories of each participating university hospital using commercially available immunoassay kits: plasma cortisol (Coat-aCount; DPC, Los Angeles, CA, USA); urinary cortisol (Cis Bio International, Gif sur Yvette, France); plasma ACTH (Brahms, Berlin, Germany). The normal range for ACTH concentrations at $0800 \mathrm{~h}$ was $2-14 \mathrm{pmol} / \mathrm{l}$. The upper limit of normal for midnight cortisol concentration was set at the mean +2 s.D. of values measured in 28 controls hospitalized for major obesity $(116 \mathrm{nmol} / \mathrm{l})$. The normal range for 2400-h UFC was $20-90 \mu \mathrm{g} / 24 \mathrm{~h}$. The circadian rhythm of plasma cortisol was considered normal if the ratio between cortisol at midnight and cortisol at $0800 \mathrm{~h}$ was less than $50 \%$. Normal level of suppression after $1 \mathrm{mg}$ DST was a plasma cortisol level below $50 \mathrm{nmol} / \mathrm{l}(1.8 \mu \mathrm{g} / \mathrm{dl})$. 
HPA axis abnormalities were therefore defined as follows: midnight plasma cortisol concentration $\geq 116 \mathrm{nmol} / \mathrm{l} ; 2400 / 0800 \mathrm{~h}$ percent cortisol ratio $\geq 50 \%$; $0800 \mathrm{~h}$ plasma ACTH concentration $\leq 2 \mathrm{pmol} / \mathrm{l}$; UFC $>135 \mu \mathrm{g} / 24 \mathrm{~h}$; and $0800 \mathrm{~h}$ plasma cortisol concentration after $1 \mathrm{mg}$ dexamethasone $\geq 50 \mathrm{nmol} / \mathrm{l}(18-21)$.

Adrenal scintigraphy Adrenal scintigraphy was performed in basal conditions, before or at least 1 week after DST, after injection of $37 \mathrm{MBq}{ }^{131} \mathrm{I}-6$ - $\beta$-iodomethylnorcholesterol (Norchol-131 CIS Bio International). Lugol's solution was administered daily, 2 days prior to and throughout the week of scanning, in order to suppress thyroid accumulation of ${ }^{131}$ I. Adrenal imaging was performed using a $\gamma$-camera equipped with a highenergy, parallel-hole collimator. Posterior and anterior abdominal images (15 min/image) were obtained on day 4-7. The interpretation of the adrenal scintigraphy was performed qualitatively by an experienced nuclear medicine physician who was blind to the result of hormonal investigations. Two types of interpretation were defined, bilateral adrenal uptake (BU), whether prevalent on the adrenal mass or symmetrical (group I); unilateral uptake (UU) concordant with the adrenal mass, with no visualization of the contralateral gland (group II).

\section{Statistical analysis}

Results were expressed as mean \pm s.D. Comparisons were based on the Fisher's exact test or $\chi^{2}$-square test for categorical variables as appropriate and the Student's $t$-test was used to compare continuous variables. For statistical purposes, the value corresponding to the limit of detection of assays was used for undetectable concentrations of plasma cortisol and ACTH ( $27 \mathrm{nmol} / \mathrm{l}$ and $1.1 \mathrm{pmol} / \mathrm{l}$ respectively). Three stepwise multiple logistic regressions were used to identify prognostic factors for the determination of patients at the risk of: hormonal progression, and tumoral progression. We evaluated scintigraphic pattern (UU versus BU) as a putative prognostic factor. Additional parameters were selected and dichotomized as appropriate: obesity (BMI cutoff, $30 \mathrm{~kg} / \mathrm{m}^{2}$ ), the presence of arterial hypertension (blood pressure cutoff: $140 / 90 \mathrm{mmHg}$ ), the presence of diabetes (glycemia cutoff: $126 \mathrm{mg} \mathrm{dl} / \mathrm{l}$ ), the presence of isolated endocrine abnormalities (below or over normal range), and tumor size (cutoff, $3.0 \mathrm{~cm}$ ). All variables that were $P<0.25$ by univariate analysis or known to be associated with hormonal or tumoral progression in previous research $(14,16)$ were entered into the logistic regression model. $P<0.05$ was considered statistically significant. Data were analyzed with SAS statistical software (release 8.01; SAS Institute, Cary, NC USA).

\section{Results}

\section{Baseline evaluation}

Sixty-one patients were enrolled in the study. Ten patients dropped out before the first year of follow-up by their own decision. Data for those patients were not taken into consideration.

According to our criteria, SCSA was found in 24 out of the 51 patients $(47 \%)$ and NSA in 27 patients $(53 \%)$. The main characteristics of patients are summarized in Table 1.

On adrenal scintigraphy, 29 out of the 51 patients (57\%) showed BU (group I) and 22 patients (43\%) showed UU (group II). Since normal UFC was mandatory to participate in the study, mean UFC was similar between the two groups of patients. However, compared with patients with BU, UU patients displayed lower $0800 \mathrm{~h}$ plasma ACTH concentration $(2.5 \pm 1.1$ vs $4.3 \pm$ $2.2 \mathrm{pmol} / \mathrm{l}, P<0.01$ ), higher plasma cortisol concentration following the overnight $1 \mathrm{mg}$ DST $(113 \pm 86 \mathrm{vs}$ $57 \pm 50 \mathrm{nmol} / \mathrm{l}, P<0.01)$ and larger tumor size $(27 \pm 7$ vs $21 \pm 8 \mathrm{~mm}, P<0.01)$. Patients in group II displayed an increased number of HPA axis abnormalities compared with group I patients $(2.1 \pm 1.2$ vs $1.1 \pm 1.1$ respectively, $P<0.05)$. Accordingly, the proportion of unilateral tumor uptake was higher in patients with SCSA than in patients with NSA (62 vs $26 \%, P<0.05)$.

\section{Follow-up study}

Fifty-one patients (28 females, 23 males; mean age $61.8 \pm 8.6$ years) with adrenocortical adenoma were followed during $4.3 \pm 1.6$ years.

Hormonal outcome In the whole group of patients, no significant change in each biological parameter was found between baseline and the latest evaluation (Table 2). However, individual evzaluation showed frequent fluctuation in the results of biochemical investigations. Thirty-five percent of HPA axis abnormalities found at baseline were no longer present at the

Table 1 Clinical, hormonal, and scintigraphic features at initial evaluation.

\begin{tabular}{lccc}
\hline Parameters & $\begin{array}{c}\text { SCSA } \\
(n=24)\end{array}$ & $\begin{array}{c}\text { NSA } \\
(n=27)\end{array}$ & $\boldsymbol{P}$ value \\
\hline Sex ratio F/M & 1.4 & 0.9 & 0.64 \\
Age (years) & $64 \pm 8$ & $61 \pm 7$ & 0.12 \\
Tumor size $(\mathrm{mm})$ & $28 \pm 7$ & $20 \pm 7$ & 0.001 \\
Midnight cortisol (nmol/l) & $189 \pm 97$ & $119 \pm 75$ & 0.009 \\
2400/0800 h cortisol ratio (\%) & $42 \pm 25$ & $23 \pm 15$ & 0.003 \\
0800 h ACTH (pmol/l) & $2.4 \pm 1.2$ & $4.5 \pm 2.1$ & 0.001 \\
24-h UFC $(\mu \mathrm{g} / 24 \mathrm{~h})$ & $45 \pm 18$ & $51 \pm 22$ & 0.29 \\
Cortisol level after 1 mg DST & $111 \pm 80$ & $52 \pm 51$ & 0.003 \\
$\quad$ (nmol/l) & & & \\
Unilateral IMS uptake & $62 \%$ & $26 \%$ & 0.008 \\
\hline
\end{tabular}

The results are expressed as mean \pm s.D. SCSA, subclinical cortisol secreting adenoma and NSA, non-secreting adenoma. 
Table 2 Hormonal parameters at initial and at the latest follow-up evaluation.

\begin{tabular}{lccc}
\hline Parameters & $\begin{array}{c}\text { Initial } \\
\text { evaluation }\end{array}$ & $\begin{array}{c}\text { Last } \\
\text { evaluation }\end{array}$ & $\boldsymbol{P}$ value \\
\hline Midnight cortisol (nmol/l) & $162 \pm 95$ & $167 \pm 75$ & 0.75 \\
2400 h/0800 h cortisol & $35 \pm 22$ & $38 \pm 22$ & 0.45 \\
$\quad$ ratio $(\%)$ & & & \\
Morning ACTH (pmol/l) & $3.5 \pm 2$ & $3.6 \pm 2$ & 0.59 \\
24-h UFC $(\mu \mathrm{g} / 24 \mathrm{~h})$ & $55 \pm 43$ & $60 \pm 33$ & 0.39 \\
Cortisol level after 1 mg & $80 \pm 72$ & $88 \pm 72$ & 0.28 \\
$\quad$ DST (nmol/l) & & & \\
\hline
\end{tabular}

The results are expressed as mean \pm S.D.

last evaluation. Among the 52 new HPA axis abnormalities that appeared in 33 patients, only 14 in 13 patients persisted at subsequent evaluations.

No case of evolution toward overt biochemical CS was observed.

Figure 1 schematizes the hormonal outcome observed. Among patients with SCSA at baseline $(n=24), 14$ patients $(58 \%)$ displayed persistent SCSA, six $(25 \%)$ patients showed hormonal progression, and four $(17 \%)$ patients showed intermittent SCSA.

Among patients with NSA at baseline $(n=27), 13$ (48\%) patients showed persistent NSA throughout the follow-up study, 11 (41\%) patients presented intermittent SCSA, and three (11\%) patients showed hormonal progression toward persistent SCSA.

Tumor size outcome On average, no variation in mass size was found between values at baseline and at the latest evaluation $(24 \pm 8$ vs $25 \pm 9 \mathrm{~mm})$. Individual evaluation revealed increases in tumor size in five patients $(10 \%)$ and decrease in one patient $(2 \%)$. Mass enlargement occurred after 1 to 5 years of follow-up, and was never associated with radiological criteria of malignancy. One patient with an increase tumor size underwent surgery: histology revealed a hematoma inside an adrenal adenoma.

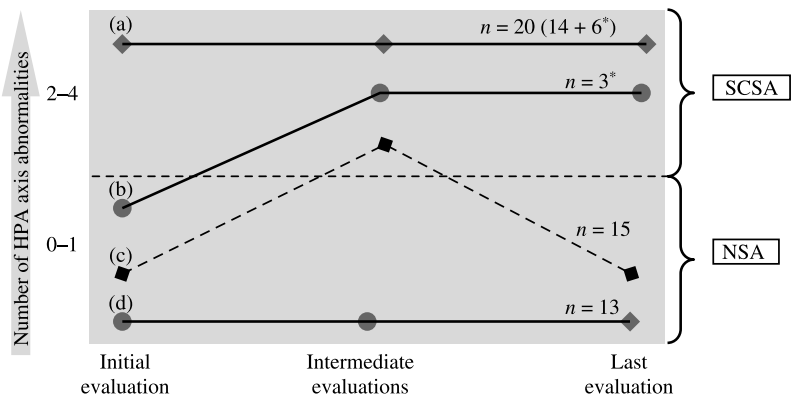

Figure 1 Illustration of hormonal evolution during follow-up. Four evolutive profiles are depicted (see methods); (a) Persistent subclinical Cushing syndrome (SCS). (b) Hormonal progression toward SCS. (c) Intermittent SCS. (d) Persistent non-secreting adenomas (NSA). Intermittent SCS included 15 adrenocortical incidentalomas characterized at baseline as SCSA $(n=4)$ and NSA $(n=11) . n^{\star}$, patients with hormonal progression.
Clinical outcome Although no patient exhibited overt biochemical CS, three patients $(6 \%)$ developed clinical signs of CS within the first 2 years of follow-up (Table 3 ). One patient had four persistent abnormalities of the HPA axis, one patient with SCSA at baseline evaluation developed a third persistent abnormality, and one patient with only impaired $1 \mathrm{mg}$ DST at baseline progressed toward SCSA. All three patients displayed unilateral radiocholesterol uptake (group II). Tumor size remained stable in each patient. All three patients underwent adrenal surgery with confirmation of benign adrenocortical adenoma. After surgery, specific signs of CS have gradually disappeared after a few years and two patients (no. 1 and 2) improved their blood pressure.

Prognostic factor analysis The persistence of biological abnormalities of the HPA axis found at baseline evaluation tended to be more frequently observed in patients with UU than in those with BU (71 vs $46 \%$ of cases, $P=0.07)$. Hormonal progression occurred in nine patients $(18 \%)$. This progression was observed within the first 2 years in eight patients and after 4 years of follow-up in one patient. Only one of these patients showed apparent adrenal mass enlargement. Among these nine patients, seven patients displayed UU at baseline. Thus, hormonal progression was more frequently observed in patients with unilateral than bilateral radiocholesterol uptake $(P<0.05)$. Overall, UU was significantly associated with persistent SCS and hormonal progression within the spectrum of SCS $(P<0.01)$. Using multivariate analysis, unilateral tumor uptake and impaired $1 \mathrm{mg}$ DST independently predicted hormonal progression (Table 4). Furthermore, no significant association between mass enlargement and scintigraphic pattern was found.

Scintigraphic evolution Twenty-three patients had a second ${ }^{131}$ I- 6 - $\beta$-iodomethylnorcholesterol scintigraphy (IMS) at the last evaluation (14 patients in group I and nine patients in group II). Among these patients, there was no difference in the interpretations of adrenal scintiscans between baseline and last evaluation.

\section{Discussion}

There are still uncertainties concerning the natural history of AI. The risk that such lesions evolve toward overt hypercortisolism are minimal and less than $1 \%$ in most studies published, whereas the development over time of new subtle biochemical abnormalities is likely to be more frequent $(11,12,16,22,30)$. Only one group reported a $12.5 \%$ estimated cumulative risk to develop overt CS after 1 year (13-15). Since the optimal duration of follow-up remains unknown $(3,12)$, the identification of prognostic factors for hormonal progression would be helpful to select patients in whom 'preventive' surgery might be indicated or in whom 
Table 3 Details of patients who displayed clinical Cushing's syndrome (CS).

\begin{tabular}{|c|c|c|c|c|c|c|}
\hline \multirow[b]{2}{*}{$\begin{array}{l}\text { Patient } \\
\text { numbers }\end{array}$} & \multirow[b]{2}{*}{$\begin{array}{l}\text { Age/Sex } \\
\text { (year) }\end{array}$} & \multicolumn{2}{|c|}{ Baseline evaluation } & \multicolumn{3}{|c|}{ Follow-up } \\
\hline & & Clinical findings & $\begin{array}{c}\text { Endocrine abnormal } \\
\text { tests }\end{array}$ & $\begin{array}{l}\text { Additional specific } \\
\text { signs of CS }\end{array}$ & $\begin{array}{l}\text { Delay of occur- } \\
\text { rence of clinical } \\
\text { CS (years) }\end{array}$ & $\begin{array}{l}\text { Endocrine abnormal } \\
\text { tests }\end{array}$ \\
\hline 1 & $62 / F$ & $\begin{array}{l}\text { Hypertension, } \\
\text { obesity }\end{array}$ & $\begin{array}{l}\text { Impaired DXM sup- } \\
\text { pression }\end{array}$ & $\begin{array}{l}\text { Skin atrophy } \\
\text { spontaneous } \\
\text { ecchymosis }\end{array}$ & 1 & $\begin{array}{l}\text { Impaired DXM sup- } \\
\text { pression, elevated } \\
\text { midnight cortisol }\end{array}$ \\
\hline 2 & $63 / F$ & $\begin{array}{l}\text { Hypertension, } \\
\text { type } 2 \text { diabetes }\end{array}$ & $\begin{array}{l}\text { Impaired DXM sup- } \\
\text { pression, low } 0800 \\
\text { ACTH, elevated } \\
\text { midnight cortisol, } \\
\text { disrupted cortisol } \\
\text { circadian rhythm }\end{array}$ & $\begin{array}{l}\text { Muscle wasting } \\
\text { skin atrophy }\end{array}$ & 2 & $\leftrightarrow$ \\
\hline 3 & $60 / \mathrm{M}$ & Hypertension & $\begin{array}{l}\text { Impaired DXM sup- } \\
\text { pression, elevated } \\
\text { midnight cortisol }\end{array}$ & $\begin{array}{l}\text { Muscle wasting } \\
\text { skin atrophy }\end{array}$ & 2 & $\begin{array}{l}\text { Impaired DXM sup- } \\
\text { pression, elevated } \\
\text { midnight cortisol, low } \\
0800 \text { ACTH }\end{array}$ \\
\hline
\end{tabular}

$\leftrightarrow$, unchanged.

prolonged and careful follow-up might be required. To date, such prognostic factors to identify patients at the risk of progression have not been well defined. A mass size $\geq 3 \mathrm{~cm}(14,16)$ and the presence of subtle biochemical endocrine abnormalities (14) have been suggested to predict evolution toward CS but are not widely accepted $(12,13)$. Only one prospective study claimed that exclusive radiocholesterol uptake by the mass at baseline evaluation was associated with an increased occurrence of cortisol hypersecretion during a 4-year follow-up (14). Thus, due to the paucity of available data on its clinical usefulness and putative redundancy with the results of biochemical investigations, radiocholesterol scintigraphy was not recommended as part of the evaluation of AI by the NIH conference consensus (3).

As expected, baseline biochemical investigation showed variable patterns of cortisol secretion amongst the adrenocortical tumors of the present study. Fortyseven percent of these showed two or more abnormal HPA axis routine tests and were considered as SCSA. In the absence of consensual definition of SCS, various biological criteria have been used across studies $(1,4$, $14,16,22,23)$. It is generally admitted that it is pertinent, from a biological perspective, to consider the diagnosis of SCS in the presence of several mild

Table 4 Putative basal predictors for hormonal progression.

\begin{tabular}{|c|c|c|c|c|c|}
\hline \multirow[b]{3}{*}{ Putative basal predictors } & \multirow[b]{3}{*}{ Numbers } & \multicolumn{4}{|c|}{ Hormonal progression } \\
\hline & & \multicolumn{2}{|c|}{ Univariate analysis } & \multicolumn{2}{|c|}{ Multivariate analysis } \\
\hline & & $P$ value & $\begin{array}{l}\text { Relative risk } \\
(\%(95 \% \mathrm{Cl}))\end{array}$ & $P$ value & $\begin{array}{l}\text { Relative risk } \\
(\%(95 \% \mathrm{Cl}))\end{array}$ \\
\hline Tumor size $<30 \mathrm{~mm}(n=35)$ & 5 & $0.35^{\mathrm{a}}$ & $2(0.4-8.7)$ & 0.15 & $0.13(0.01-2.3)$ \\
\hline Tumor $\geq 30 \mathrm{~mm}(n=16)$ & 4 & & & & \\
\hline Hypertension $(n=33)$ & 8 & $0.12^{\mathrm{a}}$ & $5.4(0.6-47.5)$ & NS & \\
\hline No hypertension $(n=18)$ & 1 & & & & \\
\hline Diabetes $(n=8)$ & 1 & 0.68 & $0.6(0.06-5.8)$ & & \\
\hline No diabetes $(n=43)$ & 8 & & & & \\
\hline Obesity $(n=17)$ & 3 & 0.92 & $1(0.2-5.1)$ & & \\
\hline No obesity $(n=34)$ & 6 & & & & \\
\hline Unilateral scintigraphic uptake $(n=22)$ & 7 & $0.03^{\mathrm{a}}$ & $6.3(1.2-34.2)$ & 0.03 & $21(1.3-345)$ \\
\hline Bilateral scintigraphic uptake $(n=29)$ & 2 & & & & \\
\hline Elevated midnight cortisol $(n=27)^{\mathrm{b}}$ & 5 & 0.86 & $1.1(0.3-4.8)$ & & \\
\hline Normal midnight cortisol $(n=24)^{\mathrm{b}^{\prime}}$ & 4 & & & & \\
\hline Disrupted cortisol rhythm $(n=8)^{\mathrm{b}}$ & $\begin{array}{l}4 \\
1\end{array}$ & 0.68 & $0.6(0.07-5.8)$ & & \\
\hline Normal cortisol rhythm $(n=43)^{b}$ & 8 & & & & \\
\hline Low morning ACTH $(n=14)^{\mathrm{b}}$ & 3 & 0.66 & $1.4(0.3-6.6)$ & & \\
\hline Normal morning ACTH $(n=37)^{\mathrm{b}}$ & 6 & & & & \\
\hline Impaired 1 mg DST $(n=29)^{\mathrm{b}}$ & 8 & $0.06^{\mathrm{a}}$ & $8(0.9-69)$ & 0.03 & $46(1.4-1500)$ \\
\hline Normal 1 mg DST $(n=22)^{\mathrm{b}}$ & 1 & & & & \\
\hline
\end{tabular}

${ }^{\text {ap }}$ arameters included in the multivariate analysis. In this model, results were adjusted for age, sex, and tumor size.

balues of the hormonal tests at baseline. 
alterations of the endocrine tests used for the diagnosis of overt CS. Consequently, we defined SCS as the presence of at least two HPA axis abnormalities with a compulsory condition of impaired suppression of serum cortisol after $1 \mathrm{mg}$ DST, a hallmark of abnormal steroid secretion with a high-negative predictive value (3). In accordance with the recent guidelines for the diagnosis of CS, we used the $50 \mathrm{nmol} / \mathrm{l}$ cutoff to enhance the sensitivity to diagnose subtle cortisol secretory autonomy (24). Several studies, including some of ours, have shown that such a low threshold may be required to diagnose subtle cortisol secretory autonomy due to adrenal tumors in patients with type 2 diabetes or osteoporosis (25-27).

A particular condition of our study was that only patients with normal UFC at baseline were included. Subtle pathological increases in nighttime cortisol secretion may not be reflected in 24-h UFC measurement $(28,29)$ and the unequivocal elevation of UFC $(>1.5 \mathrm{~N})$ reflects an increase in daily production of cortisol that we did not consider consistent with mild hypercortisolism. We therefore arbitrarily considered that an increase in UFC at baseline was not consistent with SCS but was more likely related to previously unknown, overt, CS. In accordance with previous studies, exclusive radiocholesterol uptake by the adrenal mass in our study indicated a greater degree of functional autonomy than BU and was significantly associated with biological SCS (7-9).

Although a number of retrospective studies with inherent methodological bias have been published (2), only few prospective studies provide detailed evaluation of hormonal secretion throughout follow-up (12-14). Barzon et al. (13) reported hormonal progression toward overt CS in only 4 out of the 130 patients in 5 years of follow-up. However, and in accordance with most of the prospective and retrospective studies, no evolution toward overt biochemical CS was observed in the present study $(12,16,22,30)$. This emphasizes the fact that the majority of adrenocortical incidentalomas remain hormonally and morphologically unchanged at least during a 4-year follow-up. Studies aimed at the identification of prognostic factors for evolution with adequate statistical power are therefore difficult to conduct and require a huge number of patients followed during a very long period of time. Apart from progression toward overt biochemical CS, careful analysis of biochemical investigations of the HPA axis during follow-up showed variable evolutive patterns within the spectrum of mild cortisol secretory dysregulation. Indeed, $29 \%$ of patients displayed a variable number of abnormal HPA axis tests from one evaluation to another and alternately fulfilled criteria for NSA or SCSA. Thus, and as demonstrated in overt CS of various etiology (31-33), variable hormonogenesis also occurs in SCS. This concept of intermittent SCS has seldom been mentioned $(12,22)$ but is important to consider, since the identification of an additional biochemical abnormality in the follow-up of patients with AI does not necessarily reflect a definitive progression toward overt hypercortisolism. We cannot exclude that some apparent fluctuations might be related to a lack of reproducibility of the biological tests in the range of small increases and in measuring values at the end of normal ranges (4). This is specifically of importance for putative false positives that may misclassify patients as showing hormonal progression. These findings emphasize the need for great caution in the analysis of follow-up investigations and in the decision to proceed with surgery because of subtle hormonal pattern changes. In order to limit the impact of inaccurate hormonal evaluation, additional subtle abnormalities of HPA axis that were noted during the course of observation had to persist at each evaluation to be interpreted as true hormonal progression. Interestingly, biochemical abnormalities of the HPA axis were only transient in more than half of patients with BU while they persisted in more than two-thirds of patients with UU. Thus, UU was associated with permanent abnormal cortisol secretory autonomy. In our study, $18 \%$ of patients showed established hormonal progression without occurrence of overt biochemical CS. Bernini et al. (12) reported that the estimated cumulative risk of developing subclinical endocrine abnormalities over time was $57 \%$ and progressive up to 80 months. It is important to note that, unlike Bernini et al. (12), we did not consider biological abnormalities such as elevated androgen levels in women, alterations in the reninangiotensin system or mild increases in catecholamine levels in our study. Indeed, all biochemical abnormalities that we took into account to define progression were markers of adrenal autonomy (impaired dexamethasone suppression, low $0800 \mathrm{~h}$ plasma ACTH concentration) and cortisol secretory hyperactivity (elevated midnight cortisol, disrupted cortisol circadian rhythm, and elevated 24-h UFC).

In this perspective, the main findings of our study are that exclusive radiocholesterol uptake is associated with the persistence of SCS during the follow-up and with hormonal progression. On the contrary, BU is more frequently associated with a persistent non-secreting phenotype or intermittent SCS. Using multivariate analysis, impaired $1 \mathrm{mg}$ DST and exclusive radiocholesterol uptake by the mass were significantly associated with hormonal progression. Interestingly, statistical analysis revealed that these two parameters were independent factors for hormonal progression, suggesting that their intrinsic predictive value is not redundant. One may also note that, contrary to the results of biochemical investigations, the scintigraphic pattern was very stable over time, since initial UU or BU was confirmed in every case at the end of follow-up. Although IMS provides complementary information, its routine use faces to some drawbacks. Today, the radiocholesterol analog is not available worldwide, in particular, in North America. The radiation exposure 
related to IMS is estimated to be $67 \mathrm{mSv}$ (34), i.e. approximately six times higher than that related to an abdominal CT scan. Finally, although IMS has been found cost effective in the diagnostic assessment of AI at the end of the 90s in the USA (35), the cost of the radiopharmaceutical remains relatively high in France (about 600 euros). As noted in some studies, tumor size was slightly but significantly greater in SCSA than in NSA $(16,36)$. In accordance with a previous study (12) but contrary to others $(14,16)$, tumor size was not associated with hormonal progression.

One may question the clinical relevance of subtle subclinical abnormalities of HPA axis tests and, consequently, the need to predict the evolution of an exclusively 'biochemical' disease. However, a number of studies suggest that SCS might not be completely silent and could be involved in the pathogenesis of morbid entities such as obesity, diabetes, and hypertension (23, 36-41). Thus, the identification of patients at risk of exposure to sustained mild hypercortisolism might be of interest. In addition, one may note that $6 \%$ of patients of this series who presented with SCSA, unilateral tumoral uptake and hormonal progression during follow-up, developed specific signs of clinical Cushing's without overt biochemical hypercortisolism. This suggests that, in susceptible individuals, sustained mild hypercortisolism may contribute to the development of classical features of overt CS (42). Interestingly, the resolution of 'specific' symptoms of CS such as skin bruising, proximal muscle weakness and facial plethora has been described after surgical excision of SCSA (43).

In conclusion, our study shows that mild hypercortisolism may be intermittent in almost one-third of patients with apparent SCSA and confirms that the evolution of SCSA toward overt hypercortisolism is a rare event at least in the short term $(12,13,16,22,30)$. We confirm the results of previous studies showing that UU at IMS is significantly associated with secretory autonomy of adrenocortical adenomas (7-9). In addition, we show that a unilateral scintigraphic uptake is associated with the persistence of SCS during followup and is an independent prognostic factor for hormonal progression within the spectrum of SCS. The practical usefulness of this information has to be balanced with the limitations of IMS. To date, the management of SCSA is largely empirical, since there is no evidence-based demonstration of its long-term metabolic and cardiovascular consequences (37). An ideal observational prospective study aiming to correlate the IMS pattern with the long-term clinical evolution of patients with benign adrenocortical incidentalomas is unrealistic. Elsewhere, prospective and controlled studies are needed to establish the benefits of surgical excision of SCSA versus non-surgical approach (e.g. observation associated with medical treatment of clinical abnormalities) in patients that present with hypertension, obesity, and impaired glucose tolerance. Demonstration of the superiority of surgery would provide a rationale for the use of IMS. IMS could then be performed in selected patients showing benign adrenocortical adenomas at CT scan and impaired dexamethasone suppression to assess more precisely the risk of exposure to chronic and evolutive SCS.

\section{Declaration of interest}

The authors declare that there is no conflict of interest that could be perceived as prejudicing the impartiality of the research reported.

\section{Funding}

This study was supported by the Programme Hospitalier de Recherche Clinique (PHRC).

\section{References}

1 Mantero F, Terzolo M, Arnaldi G, Osella G, Masini AM, Ali A, Giovagnetti M, Opocher G \& Angeli A. A survey on adrenal incidentaloma in Italy. Study Group on Adrenal Tumors of the Italian Society of Endocrinology. Journal of Clinical Endocrinology and Metabolism 200085 637-644.

2 Mansmann G, Lau J, Balk E, Rothberg M, Miyachi Y \& Bornstein SR. The clinically inapparent adrenal mass: update in diagnosis and management. Endocrine Reviews 200425 309-340.

3 Grumbach MM, Biller BM, Braunstein GD, Campbell KK, Carney JA, Godley PA, Harris EL, Lee JK, Oertel YC, Posner MC, Schlechte JA \& Wieand HS. Management of the clinically inapparent adrenal mass ('incidentaloma'). Annals of Internal Medicine 2003138 424-429.

4 Terzolo M, Bovio S, Reimondo G, Pia A, Osella G, Borretta G \& Angeli A. Subclinical Cushing's syndrome in adrenal incidentalomas. Endocrinology and Metabolism Clinics of North America 2005 34 423-439 (x).

5 Beierwaltes WH, Sturman MF, Ryo U \& Ice RD. Imaging functional nodules of the adrenal glands with 131-I-19-iodocholesterol. Journal of Nuclear Medicine 197415 246-251.

6 Charbonnel B, Chatal JF \& Ozanne P. Does the corticoadrenal adenoma with 'pre-Cushing's syndrome' exist? Journal of Nuclear Medicine 198122 1059-1061.

7 Bardet S, Rohmer V, Murat A, Guillemot C, Marechaud R, Chupin M, Lecomte P, Simon D, Delemer B, Schneebelli S, Beutter D, Jacquin V, Peltier P \& Charbonnel B. ${ }^{131} \mathrm{I}-6$ Betaiodomethylnorcholesterol scintigraphy: an assessment of its role in the investigation of adrenocortical incidentalomas. Clinical Endocrinology $1996 \mathbf{4 4} 587-596$.

8 Valli N, Catargi B, Ronci N, Vergnot V, Leccia F, Ferriere JM, Chene G, Grenier N, Laurent F \& Tabarin A. Biochemical screening for subclinical cortisol-secreting adenomas amongst adrenal incidentalomas. European Journal of Endocrinology $2001 \mathbf{1 4 4}$ 401-408.

9 Barzon L, Scaroni C, Sonino N, Fallo F, Gregianin M, Macri C \& Boscaro M. Incidentally discovered adrenal tumors: endocrine and scintigraphic correlates. Journal of Clinical Endocrinology and Metabolism 199883 55-62.

10 Imperiale A, Olianti C, Mannelli M, La Cava G \& Pupi A. Tomographic evaluation of [131I] 6beta-iodomethyl-norcholesterol standardised uptake trend in clinically silent monolateral and bilateral adrenocortical incidentalomas. Quarterly Journal of Nuclear Medicine and Molecular Imaging 200549 287-296.

11 Bulow B, Jansson S, Juhlin C, Steen L, Thoren M, Wahrenberg H, Valdemarsson S, Wangberg B \& Ahreen B. Adrenal incidentaloma - follow-up results from a Swedish prospective study. European Journal of Endocrinology $2006 \mathbf{1 5 4} 419-423$. 
12 Bernini GP, Moretti A, Oriandini C, Bardini M, Taurino C \& Salvetti A. Long-term morphological and hormonal follow-up in a single unit on 115 patients with adrenal incidentalomas. British Journal of Cancer 200592 1104-1109.

13 Barzon L, Fallo F, Sonino N \& Boscaro M. Development of overt Cushing's syndrome in patients with adrenal incidentaloma. European Journal of Endocrinology 2002146 61-66.

14 Barzon L, Scaroni C, Sonino N, Fallo F, Paoletta A \& Boscaro M. Risk factors and long-term follow-up of adrenal incidentalomas. Journal of Clinical Endocrinology and Metabolism $199984520-526$.

15 Barzon L, Sonino N, Fallo F, Palu G \& Boscaro M. Prevalence and natural history of adrenal incidentalomas. European Journal of Endocrinology 2003149 273-285.

16 Libe R, Dall'asta C, Barbetta L, Baccarelli A, Beck-Peccoz P \& Ambrosi B. Long-term follow-up study of patients with adrenal incidentalomas. European Journal of Endocrinology 2002147 489-494.

17 Caoili EM, Korobkin M, Francis IR, Cohan RH, Platt JF, Dunnick NR \& Raghupathi KI. Adrenal masses: characterization with combined unenhanced and delayed enhanced CT. Radiology 2002222 629-633.

18 Tsagarakis S, Kokkoris P, Roboti C, Malagari C, Kaskarelis J, Vlassopoulou V, Alevizaki C \& Thalassinos N. The low-dose dexamethasone suppression test in patients with adrenal incidentalomas: comparisons with clinically euadrenal subjects and patients with Cushing's syndrome. Clinical Endocrinology 199848 627-633.

19 Tsagarakis S, Roboti C, Kokkoris P, Vasiliou V, Alevizaki C \& Thalassinos N. Elevated post-dexamethasone suppression cortisol concentrations correlate with hormonal alterations of the hypothalamo-pituitary-adrenal axis in patients with adrenal incidentalomas. Clinical Endocrinology 199849 165-171.

20 Huizenga NA, Koper JW, De Lange P, Pols HA, Stolk RP, Grobbee DE, De Jong FH \& Lamberts SW. Interperson variability but intraperson stability of baseline plasma cortisol concentrations, and its relation to feedback sensitivity of the hypothalamo-pituitary-adrenal axis to a low dose of dexamethasone in elderly individuals. Journal of Clinical Endocrinology and Metabolism $19988347-54$.

21 Findling JW, Raff $\mathrm{H} \&$ Aron DC. The low-dose dexamethasone suppression test: a reevaluation in patients with Cushing's syndrome. Journal of Clinical Endocrinology and Metabolism 2004 89 1222-1226.

22 Terzolo M, Osella G, Ali A, Borretta G, Cesario F, Paccotti P \& Angeli A. Subclinical Cushing's syndrome in adrenal incidentaloma. Clinical Endocrinology 199848 89-97.

23 Rossi R, Tauchmanova L, Luciano A, Di Martino M, Battista C, Del Viscovo L, Nuzzo V \& Lombardi G. Subclinical Cushing's syndrome in patients with adrenal incidentaloma: clinical and biochemical features. Journal of Clinical Endocrinology and Metabolism $2000 \mathbf{8 5}$ 1440-1448.

24 Nieman LK, Biller BM, Findling JW, Newell-Price J, Savage MO, Stewart PM \& Montori VM. The diagnosis of Cushing's syndrome: an Endocrine Society Clinical Practice Guideline. Journal of Clinical Endocrinology and Metabolism 200893 1526-1540.

25 Catargi B, Rigalleau V, Poussin A, Ronci-Chaix N, Bex V, Vergnot V, Gin H, Roger P \& Tabarin A. Occult Cushing's syndrome in type-2 diabetes. Journal of Clinical Endocrinology and Metabolism $2003 \mathbf{8 8}$ 5808-5813.

26 Chiodini I, Torlontano M, Scillitani A, Arosio M, Bacci S, Di Lembo S, Epaminonda P, Augello G, Enrini R, Ambrosi B, Adda G \& Trischitta V. Association of subclinical hypercortisolism with type 2 diabetes mellitus: a case-control study in hospitalized patients. European Journal of Endocrinology 2005153 837-844.

27 Chiodini I, Mascia ML, Muscarella S, Battista C, Minisola S, Arosio M, Santini SA, Guglielmi G, Carnevale V \& Scillitani A. Subclinical hypercortisolism among outpatients referred for osteoporosis. Annals of Internal Medicine 2007147 541-548.
28 Findling JW \& Raff H. Screening and diagnosis of Cushing's syndrome. Endocrinology and Metabolism Clinics of North America 200534 385-402 (ix-x).

29 Kidambi S, Raff H \& Findling JW. Limitations of nocturnal salivary cortisol and urine free cortisol in the diagnosis of mild Cushing's syndrome. European Journal of Endocrinology 2007157 725-731.

30 Grossrubatscher E, Vignati F, Possa M \& Lohi P. The natural history of incidentally discovered adrenocortical adenomas: a retrospective evaluation. Journal of Endocrinological Investigation 2001 24 846-855.

31 Boscaro M, Barzon L, Fallo F \& Sonino N. Cushing's syndrome. Lancet 2001357 783-791.

32 Arnaldi G, Angeli A, Atkinson AB, Bertagna X, Cavagnini F, Chrousos GP, Fava GA, Findling JW, Gaillard RC, Grossman AB, Kola B, Lacroix A, Mancini T, Mantero F, Newell-Price J, Nieman LK, Sonino N, Vance ML, Giustina A \& Boscaro M. Diagnosis and complications of Cushing's syndrome: a consensus statement. Journal of Clinical Endocrinology and Metabolism 2003 88 5593-5602.

33 Meinardi JR, Wolffenbuttel BH \& Dullaart RP. Cyclic Cushing's syndrome: a clinical challenge. European Journal of Endocrinology $2007157245-254$.

34 Radiation dose to patients from radiopharmaceuticals (addendum 2 to ICRP publication 53). Annals of the ICRP 199828 1-126.

35 Dwamena BA, Kloos RT, Fendrick AM, Gross MD, Francis IR, Korobkin MT \& Shapiro B. Diagnostic evaluation of the adrenal incidentaloma: decision and cost-effectiveness analyses. Journal of Nuclear Medicine 199839 707-712.

36 Reincke M, Nieke J, Krestin GP, Saeger W, Allolio B \& Winkelmann W. Preclinical Cushing's syndrome in adrenal 'incidentalomas': comparison with adrenal Cushing's syndrome. Journal of Clinical Endocrinology and Metabolism 199275 826-832.

37 Angeli A \& Terzolo M. Adrenal incidentaloma - a modern disease with old complications. Journal of Clinical Endocrinology and Metabolism 200287 4869-4871.

38 Terzolo M, Pia A, Ali A, Osella G, Reimondo G, Bovio S, Daffara F, Procopio M, Paccotti P, Borretta G \& Angeli A. Adrenal incidentaloma: a new cause of the metabolic syndrome? Journal of Clinical Endocrinology and Metabolism 2002 87 998-1003.

39 Tauchmanova L, Rossi R, Biondi B, Pulcrano M, Nuzzo V, Palmieri EA, Fazio S \& Lombardi G. Patients with subclinical Cushing's syndrome due to adrenal adenoma have increased cardiovascular risk. Journal of Clinical Endocrinology and Metabolism $2002874872-4878$.

40 Bernini G, Moretti A, Iacconi P, Miccoli P, Nami R, Lucani B \& Salvetti A. Anthropometric, haemodynamic, humoral and hormonal evaluation in patients with incidental adrenocortical adenomas before and after surgery. European Journal of Endocrinology $2003 \mathbf{1 4 8} 213-219$.

41 Erbil Y, Ademoglu E, Ozbey N, Barbaros U, Yanik BT, Salmaslioglu A, Bozbora A \& Ozarmagan S. Evaluation of the cardiovascular risk in patients with subclinical Cushing syndrome before and after surgery. World Journal of Surgery 200630 1665-1671.

42 Huizenga NA, Koper JW, De Lange P, Pols HA, Stolk RP, Burger H, Grobbee DE, Brinkmann AO, De Jong FH \& Lamberts SW. A polymorphism in the glucocorticoid receptor gene may be associated with and increased sensitivity to glucocorticoids in vivo. Journal of Clinical Endocrinology and Metabolism 1998 83 144-151.

43 Mitchell IC, Auchus RJ, Juneja K, Chang AY, Holt SA, Snyder WH III \& Nwariaku FE. 'Subclinical Cushing's syndrome' is not subclinical: improvement after adrenalectomy in 9 patients. Surgery $2007 \mathbf{1 4 2}$ 900-905.

Received 5 October 2008

Accepted 18 October 2008 